\title{
Development of an Electrochemical Sensor for Catecholamine Detection via a Layer-by-layer Fabrication Method
}

\author{
Ruzheng $\mathrm{Han}^{1 \#}$, Jun $\mathrm{Ma}^{2 \# *}$ and Limin $\mathrm{He}^{2}$ \\ ${ }^{1}$ Department of Neurosurgery, Weihaiwei People's Hospital,Weihai 264200,P.R. China \\ ${ }^{2}$ Department of Neurosurgery, 404 Central Hospital of The People's Liberation Army, Weihai, \\ 264200, P.R. China \\ \#These authors contributed equally to this work. \\ *E-mail: junma.826@ foxmail.com
}

doi: $10.20964 / 2017.11 .46$

Received: 18 July 2017 / Accepted: 5 September 2017 / Published: 12 October 2017

In this work, the $\mathrm{Cu} / \mathrm{MnO} 2 / \mathrm{MWCNTs}$ (MWCNTs) nanocomposite modified glass carbon electrode (GCE) was applied to the preparation of a novel sensor of catecholamine (CA) using an electrochemical strategy. Amperometry was used to investigate the electrocatalytic activity of this sensor in CA oxidation. It was found that the current response had a linear relationship with the concentration of glucose $(0.65-2000 \mu \mathrm{M})$, and the correlation coefficient was 0.99 . Meanwhile, the limit of detection (LOD) was calculated as $0.14 \mu \mathrm{M}(\mathrm{S} / \mathrm{N}=3)$, and the response time was $3 \mathrm{~s}$.

Keywords: Neurotransmitter Catecholamine; Layer-by-layer; Electrochemical determination; Cerebrovascular diseases

\section{FULL TEXT}

(C) 2017 The Authors. Published by ESG (www.electrochemsci.org). This article is an open access article distributed under the terms and conditions of the Creative Commons Attribution license (http://creativecommons.org/licenses/by/4.0/). 